\title{
Формирование информации о рисках в корпоративном учете и отчетности
}

\begin{abstract}
АННОТАЦИЯ
В статье рассматривается воздействие практики управления рисками на повышение конкурентоспособности и финансовой устойчивости корпораций. Целью исследования является разработка рекомендаций по формированию в бухгалтерском учете и раскрытию в бухгалтерской (финансовой) отчетности информации о рисках, присущих деятельности корпораций, необходимость которой отмечена документом Минфина России «Информация № П3-9/2012»*. Критический анализ типологий рисков, представленных в работах отечественных и зарубежных исследователей, позволил сделать вывод об их количественном возрастании, в том числе в связи с остановкой и сбоями производства вследствие гибели и повреждения активов (оборудования, транспорта, сырья), перенапряжением технической и технологической систем, проблемами неадекватного использования сырья, ростом издержек, иными факторами.

Введено понятие риска утраты собственного капитала корпорации, который возникает при снижении стоимости активов и может быть выявлен при их тестировании на обесценение, что обеспечивает надежность оценки объектов в бухгалтерской (финансовой) отчетности. Оценка рисков, основанная на допущении, что активы отражены в надежном стоимостном измерении на соответствующих счетах и в учетных регистрах, является одним из элементов внутреннего контроля корпорации и позволяет пользователям принять обоснованные экономические решения. Тестирование на обесценение предполагает выявление характерных для определенных активов внешних и внутренних признаков, расчет суммы обесценения, систематизацию и раскрытие информации в учете и отчетности. В связи с этим сделан вывод о необходимости включения в документах Минфина России рисков утраты собственного капитала из-за обесценения активов в состав рисков, подлежащих раскрытию в бухгалтерской (финансовой) отчетности. Доказано, что их анализ и оценка предполагают выявление рискообразующих факторов, определение уровня риска, разработку мероприятий по его снижению, поэтому систематизацию информации о рисках целесообразно осуществлять в корпоративных стандартах учета и отчетности, применение которых рекомендовано Федеральным законом «О бухгалтерском учете»**.

Ключевые слова: риски; контроль; оценка активов; оценочные резервы; тестирование активов на обесценение; мнимые объекты учета
\end{abstract}

Для цитирования: Сапожникова Н.Г. Формирование информации о рисках в корпоративном учете и отчетности. Учет. Анализ.Aудum = Accounting.Analysis.Auditing. 2021;8(5):41-54. DOI: 10.26794/2408-9303-2021-8-5-41-54

\section{Formation of Risks' Information in Corporate Accounting and Reporting}

\author{
N.G. Sapozhnikova \\ Voronezh State University, Voronezh, Russia \\ http://orcid.org/0000-0003-2563-6198
}

\section{ABSTRACT}

The paper examines the impact of risk management practices on improving the competitiveness and financial stability of corporations. The purpose of the study is to develop recommendations for the formation in

\footnotetext{
* Информация Минфина России № П3-9/2012 «О раскрытии информации о рисках хозяйственной деятельности организации в годовой бухгалтерской отчетности». URL: http://www.consultant.ru/document/cons_doc_LAW_135436/ (дата обращения: 21.07.2021). ** Информация Минфина России № П3-10/2012 «О вступлении в силу с 1 января 2013 г. Федерального закона от 6 декабря 2011 г. № 402-Ф3 “О бухгалтерском учете”». URL: http://www.consultant.ru/document/cons_doc_LAW_138570/ (дата обращения: 21.07.2021)
} 
accounting and disclosure in the accounting (financial) statements of information about the risks inherent in the activities of corporations. The need for the above is noted by the document of the Ministry of Finance of Russia "Information No. PZ-9/2012"*. A critical analysis of the risks typologies presented in the studies of domestic and foreign researchers that had allowed to draw a conclusion about their quantitative increase in the number of risks of corporations including such as: stoppages and disruptions of production due to the death and damage of assets (equipment, transport, raw materials); overvoltage of technical and technological systems; problems inadequate use of raw materials; rising costs and other factors. The author introduces the concept of the risk of loss of a corporation's equity capital caused by a decrease in the value of assets, which can be identified by impairment testing, which ensures the reliability of the assessment of the accounting objects and elements of accounting (financial) statements. Risk assessment based on the assumption that assets are shown in reliable value in the appropriate accounts and ledgers, is one of the elements of internal control of the corporation and allows users to make informed economic decisions. Impairment testing involves the identification of external and internal indicators characteristic of certain assets, the calculation of the amount of impairment, systematization and disclosure of information in accounting and reporting. Along with the recommended risks typology it is advisable for the Ministry of Finance of Russia to include in the list of risks to be disclosed in the accounting (financial) statements, the risks of loss of equity capital due to asset depreciation. It has been proven that the analysis and assessment involve identifying risk-forming factors, determining the level of risk and developing measures to reduce the risk. Therefore, it is expediently to systematize the risk information in corporate accounting and reporting standards, the use of which is recommended by the Federal Law "On Accounting"**.

Keywords: risks; control; asset valuation; estimated reserves; testing of assets for impairment; imaginary accounting objects

For citation: Sapozhnikova N.G. Formation of risks' information in corporate accounting and reporting. Uchet. Analysis. Audit = Accounting. Analysis. Auditing. 2021;8(5):41-54. (In Russ.). DOI: 10.26794/2408-9303-2021-8-5-41-54

\section{ВВЕДЕНИЕ}

Современный этап развития корпоративной отчетности характеризуется институциональными изменениями, связанными с принятием ряда нормативных актов, в соответствии с которыми корпорации обязаны организовывать и осуществлять внутренний контроль совершаемых фактов хозяйственной жизни, а те из них, которые подлежат обязательному аудиту - осуществлять внутренний контроль ведения учета и составления корпоративной отчетности. Внутренний контроль фактов хозяйственной жизни - это процесс, направленный на получение достаточной уверенности в том, что корпорация обеспечивает:

- эффективность и результативность деятельности, в т.ч. достижение финансовых и операционных показателей;

- сохранность активов;

- достоверность и своевременность корпоративной отчетности;
- соблюдение законодательства при совершении фактов хозяйственной жизни и их отражении в учете.

Его основными элементами являются контрольная среда, оценка рисков, процедуры и оценка внутреннего контроля, информация и коммуникации. Обычно под риском понимается сочетание вероятности и последствий недостижения корпорацией целей деятельности, а оценка рисков определяется как процесс их выявления и анализа. Обнаружение рисков позволяет принять решения по управлению ими посредством создания необходимой контрольной среды, организации процедур внутреннего контроля и оценки его результатов, информирования персонала. При оценивании рисков, влияющих на достоверность ведения корпоративного учета и составления корпоративной отчетности, рассматривается вероятность искажения учетных и отчетных данных на основании следующих допущений:

\footnotetext{
* Information of the Ministry of Finance of Russia No. PZ-9/2012 "On disclosure of information on the risks of economic activities of the organization in the annual financial statements". URL: http://www.consultant.ru/document/cons_doc_LAW_135436/ (accessed: 21.07.2021).

** Information of the Ministry of Finance of Russia No. PZ-10/2012 "On the entry into force from January 1, 2013 of the Federal Law of December 6, 2011 No. 402-FZ “On accounting’”. URL: http://www.consultant.ru/ document / cons_doc_LAW_138570 / (accessed: 21.07.2021).
} 
- возникновение и существование - факты хозяйственной жизни, отраженные в корпоративном учете, имели место в отчетном периоде и относятся к деятельности корпорации;

- полнота - факты хозяйственной жизни, имевшие место в отчетном периоде и подлежащие отнесению к нему, фактически отражены в корпоративном учете;

- права и обязательства - отраженные в корпоративном учете активы, права и обязательства корпорации фактически существуют;

- оценка и распределение - активы, обязательства, доходы и расходы отражены в надежном стоимостном измерении на соответствующих счетах и в учетных регистрах;

- представление и раскрытие - данные учета представлены и раскрыты в корпоративной отчетности корректно.

Гражданским кодексом Российской Федерации ${ }^{1}$ предпринимательский риск определяется как «риск убытков от предпринимательской деятельности из-за нарушения своих обязательств контрагентами предпринимателя или изменения условий этой деятельности по независящим от предпринимателя обстоятельствам, в том числе риск неполучения ожидаемых доходов».

В настоящее время в экономической литературе, исследующей риски, предлагаются различные их классификации. Например, Й. Шумпетер [1] рассматривал два вида риска: связанный с возможным техническим провалом производства (сюда же мы можем отнести также опасность потери благ, порожденную стихийными бедствиями) и сопряженный с отсутствием коммерческого успеха. Несколько видов производственного риска представлены в современных экономических исследованиях [2-8] (табл. 1).

Наряду с производственными рисками, И.Т. Балабанов [9] выделяет имущественные риски, связанные с вероятностью потерь имущества предпринимателя по причине кражи, диверсии, халатности, перенапряжения технической и технологической систем. Понятие имущественного риска представлено в работе С.А. Бороненковой, И.Е. Власовой, Т.И. Буяновой, где четко написано: «Практика показывает, что наиболее часто возникают рисковые события по имуществен-

\footnotetext{
${ }^{1}$ Гражданский кодекс Российской Федерации (ГК РФ). URL: http://www.consultant.ru/document/cons_doc_LAW_5142/ (дата обращения: 21.07.2021).
}

ным рискам. К имущественным рискам можно отнести обесценение активов: основных средств, нематериальных активов, финансовых вложений, снижение стоимости материальных ценностей и сомнительные долги» [13].

Типология факторов риска, представленная в ряде работ [3, 9, 11, 14], включает, в частности, факторы прямого и косвенного воздействия. В качестве первых рассматриваются: изменение законодательства, регулирующего предпринимательскую деятельность; конкуренцию предпринимателей; взаимоотношения с хозяйствующими партнерами; налоговую систему; коррупцию и рэкет, а в качестве факторов косвенного воздействия выступают политическая обстановка, международные события, экономическая неустойчивость страны деятельности, стихийные бедствия.

\section{МЕТОДЫ И РЕЗУЛЬТАТЫ ИССЛЕДОВАНИЯ}

В документе Минфина РФ № ПЗ 11/2013 «Об организации и осуществлении экономическим субъектом внутреннего контроля совершаемых фактов хозяйственной жизни, ведения бухгалтерского учета и составления бухгалтерской (финансовой) отчетности» ${ }^{2}$ предусматривается включение оценки рисков в состав элементов внутреннего контроля наряду с контрольной средой, процедурами и оценкой, а под риском понимается сочетание вероятности и последствий недостижения корпорацией целей деятельности. Своевременное выявление и анализ рисков составляют основу процедуры оценки и обеспечивают принятие обоснованных экономических решений, а оценка рисков обеспечивает достоверность сведений бухгалтерского учета и бухгалтерской (финансовой) отчетности.

Производственные, имущественные, операционные риски способствуют возникновению убытков, влияющих на величину собственного капитала корпорации, поэтому одним из направлений исследования является оценка риска возникновения нарушений, связанных с приобретением и использованием активов, ведением корпоративного учета и формирования корпоративной отчетности.

${ }^{2}$ П3 - 11/2013 «Об организации и осуществлении экономическим субъектом внутреннего контроля совершаемых фактов хозяйственной жизни, ведения бухгалтерского учета и составления бухгалтерской (финансовой) отчетности». URL: http://www.consultant.ru/document/cons_doc LAW_156407/ (дата обращения: 21.07.2021). 
Подходы к определению производственного риска / Approaches to determining production risk

\begin{tabular}{|c|c|}
\hline Авторы / Authors & Определения риска / Risk definitions \\
\hline $\begin{array}{l}\text { Балабанов И.Т.// } \\
\text { Balabanov I.T. [9] }\end{array}$ & $\begin{array}{l}\text { Риски, связанные с убытком от остановки производства вследствие воздействия } \\
\text { различных факторов и прежде всего гибелью или повреждением основных и оборотных } \\
\text { фондов (оборудование, сырье, транспорт и т.п.), а также риски, связанные с внедрением } \\
\text { в производство новой техники и технологии / Risks associated with the loss from the shutdown } \\
\text { of production due to the impact of various factors and, above all, the death or damage of fixed } \\
\text { and current assets (equipment, raw materials, transport, etc.), as well as risks associated with the } \\
\text { introduction of new equipment and technology into production }\end{array}$ \\
\hline $\begin{array}{l}\text { Морозов Д.С./ } \\
\text { Morozov D.S. [10] }\end{array}$ & $\begin{array}{l}\text { Риск возникновения сбоев в производственном процессе - может выражаться в нарушении } \\
\text { ритмичности производства, или даже полной остановке производства, невыходе объекта } \\
\text { на проектную мощность, повышенном проценте брака, дополнительных производственных } \\
\text { издержках и т.д./ The risk of failures in the production process can be expressed in a violation } \\
\text { of the rhythm of production, or even a complete stop of production, the failure of the object to } \\
\text { reach its design capacity, an increased percentage of defects, additional production costs, etc. }\end{array}$ \\
\hline $\begin{array}{c}\text { Лапуста М.Г., } \\
\text { Шаршукова Л.Г./ } \\
\text { Lapusta M.G., } \\
\text { Sharshukova L.G. [11] }\end{array}$ & $\begin{array}{l}\text { Риск, связанный с производством продукции, товаров и услуг; с осуществлением любых } \\
\text { видов производственной деятельности, в процессе которой предприниматели сталкиваются } \\
\text { с проблемами неадекватного использования сырья, роста себестоимости, увеличения потерь } \\
\text { рабочего времени, использования новых методов производства / The risk is associated } \\
\text { with the production of products, goods and services; with the implementation of any types } \\
\text { of production activities, during which entrepreneurs face problems of inadequate use of raw } \\
\text { materials, cost growth, increased loss of working time, the use of new production methods }\end{array}$ \\
\hline $\begin{array}{c}\text { Федорец А.Г./ } \\
\text { Fedorets A.G. [12] }\end{array}$ & $\begin{array}{l}\text { Риск, связанный с особенностями конкретного производства с учетом применяемой } \\
\text { технологии, системы менеджмента, условий труда. Включает все факторы, оказывающие } \\
\text { воздействие на работников различных профессий в процессе их трудовой деятельности, } \\
\text { и имеет отношение к производству (виду деятельности, предприятию или отрасли в целом) / } \\
\text { The risk related to the specifics of a particular production, taking into account the applied } \\
\text { technology, management system, working conditions. It includes all factors that affect employees } \\
\text { of various professions in the course of their work and is related to production (type of activity, } \\
\text { enterprise or industry as a whole) }\end{array}$ \\
\hline
\end{tabular}

Источник / Source: разработано автором / developed by the author.

При этом должны выявляться причины возможности их совершения, в т.ч. вследствие недостатков контрольной среды и процедур внутреннего контроля корпорации.

Требования к организации системы внутреннего контроля корпорации предусмотрены приказом ФНС РФ № ММВ-7-15/509³, содержащим формы рабочих документов и методику балльной оценки контроля. Приказ ФНС и Информация Минфина России П3-11/2013 отмечают, что для обеспечения организации и функционирования внутреннего контроля корпорации необходимо разработать систему управления рисками. Отдельные элементы такой системы представлены в табл. 2.

\footnotetext{
${ }^{3}$ Приказ ФНС России от 16.06.2017 № ММВ-7-15/509@ «Об утверждении Требований к организации системы внутреннего контроля» (Зарегистрировано в Минюсте России 04.10.2017 № 48424). URL: http://www.consultant. ru/document/cons_doc_LAW_279362//(дата обращения: 21.07.2021).
}

Содержимое табл. 2 позволяет сделать вывод об идентичности компонентов Требований ФНС и элементов Информации Минфина РФ, что обеспечивает единство формирования учетной политики для целей корпоративного учета и проведения налоговых расчетов.

Важным элементом системы управления рисками является обеспечение надежной оценки активов, обязательств, доходов и расходов на соответствующих счетах и в регистрах корпоративного учета, а также корректное представление элементов отчетности. Производственные риски, по убеждению автора, могут быть связаны не только с гибелью и повреждением внеоборотных и оборотных активов, но также с их обесценением, способствующим утрате корпорацией собственного капитала. Необходимость систематизации в учете и раскрытия в бухгалтерской (финансовой) отчетности информации об изменении оценки активов также отмечалась рядом авторов [14-18]. 
Элементы системы управления рисками в различных нормативно-правовых документах / Elements of the risk management system in various regulatory documents

\begin{tabular}{|c|c|}
\hline $\begin{array}{l}\text { Информация Минфина России № ПЗ-11/2013 / Information of the } \\
\text { Ministry of Finance of the Russian Federation No. PZ-11/2013 }\end{array}$ & $\begin{array}{l}\text { Требования ФНС России к организации } \\
\text { системы внутреннего контроля / } \\
\text { Requirements of the Federal Tax Service of } \\
\text { Russia for the organization of the internal } \\
\text { control system }\end{array}$ \\
\hline 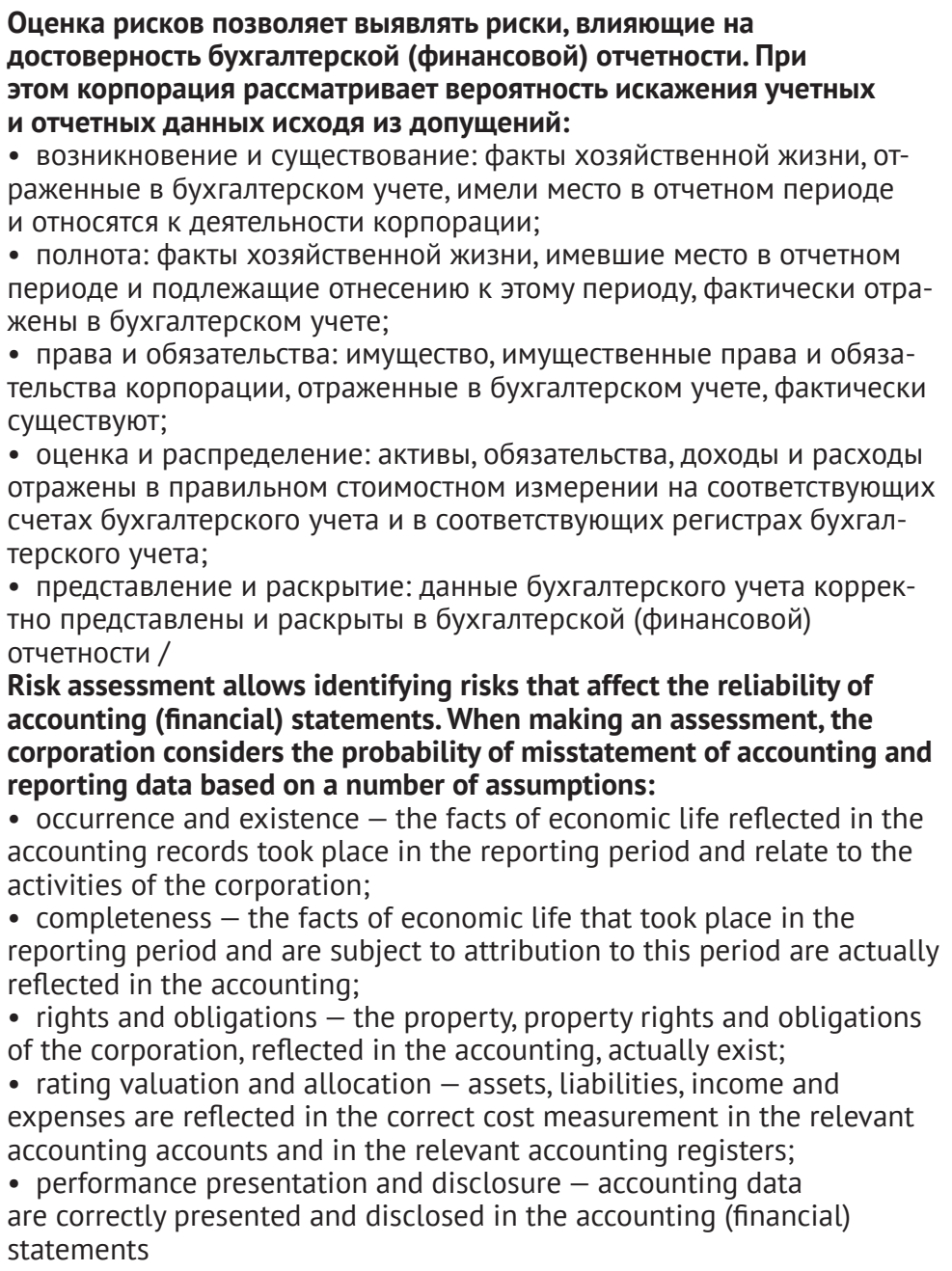 & $\begin{array}{l}\text { Оценка корпорацией рисков: } \\
\text { - вероятность наступления риска; } \\
\text { - оценка искажений показателей бухгал- } \\
\text { терской (финансовой), налоговой и иной } \\
\text { отчетности; } \\
\text { - определение уровня риска. } \\
\text { Раскрытие информации о рисках } \\
\text { корпорации: } \\
\text { - сведения об источниках возникновения } \\
\text { риска, критериях риска, минимизации риска; } \\
\text { - направления выявления рисков; } \\
\text { - осуществление инвестиционной деятель- } \\
\text { ности; } \\
\text { - реорганизация; } \\
\text { - реструктуризация деятельности; } \\
\text { - иные / } \\
\text { Сorporate risk disclosure: } \\
\text { the probability of risk ocсurrence; } \\
\text { аssessment of distortions in aсcounting } \\
\text { (financial), tax and other reporting indicators; } \\
\text { determining the level of risk. } \\
\text { Disclosure of information about the risks } \\
\text { of the corporation: } \\
\text { - information about the sources of risk, risk } \\
\text { criteria, risk minimization; } \\
\text { - areas of risk identification; } \\
\text { - implementation of investment activities; } \\
\text { - reorganization; } \\
\text { - restructuring of activities; } \\
\text { - others }\end{array}$ \\
\hline
\end{tabular}

Источник / Source: разработано автором / developed by the author.

Активами, присущими корпорациям, являются запасы, оцениваемые на отчетную дату по наименьшей из следующих величин:

а) фактическая себестоимость;

б) чистая стоимость продажи (табл. 3).

Обесценением запасов признается превышение фактической себестоимости запасов над их чистой стоимостью продажи. Признаки обесценение запасов характеризует рис. 1.
Признаки обесценения запасов взаимосвязаны и взаимозависимы; например, моральное устаревание, снижение рыночной стоимости и потеря первоначальных качеств материалов может происходить в результате сужения рынков сбыта. В свою очередь, наличие названных признаков приводит к сужению рынка сбыта материалов. Основной причиной обесценения материалов является длительное пребывание на складе кор- 


\section{Методы оценки запасов / Inventory estimation methods}

\begin{tabular}{|c|c|}
\hline $\begin{array}{l}\text { Методы оценки / } \\
\text { Evaluation methods }\end{array}$ & Порядок расчета / Calculation procedure \\
\hline $\begin{array}{l}\text { Фактическая } \\
\text { себестоимость / } \\
\text { Actual cost price }\end{array}$ & $\begin{array}{l}\text { Фактические затраты на приобретение (создание) запасов, их расположение и приведение } \\
\text { их в состояние, необходимые для потребления, продажи или использования / The actual } \\
\text { costs of acquiring (creating) stocks, bringing them into condition and location necessary for } \\
\text { consumption, sale or use }\end{array}$ \\
\hline $\begin{array}{l}\text { Чистая стоимость / } \\
\text { Net value }\end{array}$ & $\begin{array}{l}\text { Определяется корпорацией как предполагаемая цена, по которой можно продать запасы } \\
\text { в том виде, в котором она обычно продает их в ходе обычной деятельности, за вычетом } \\
\text { предполагаемых затрат, необходимых для их производства, подготовки к продаже } \\
\text { и осуществления продажи. За чистую стоимость продажи запасов принимается величина, } \\
\text { равная приходящейся на данные материалы доле предполагаемой цены, по которой } \\
\text { корпорация может продать готовую продукцию, работы, услуги, в производстве которых } \\
\text { используются указанные запасы. Если определение указанной величины является } \\
\text { затруднительным, то за чистую стоимость продажи материалов может быть принята цена, } \\
\text { по которой возможно приобрести аналогичные материалы по состоянию на отчетную дату / } \\
\text { It is defined by the corporation as the estimated price at which it is pоssible to sell stocks in } \\
\text { the form in which it usually sells them in the ordinary course of business, minus the estimated } \\
\text { costs necessary for their production, preparation for sale and implementation of the sale. For } \\
\text { the net value of the sale of stocks, an amount equal to the share of the estimated price at } \\
\text { which the corporation can sell its products, works, services, in the production of which these } \\
\text { stocks are used, is assumed to be equal to the share of the estimated price for these materials. } \\
\text { If it is difficult to determine the specified value, the net cost of selling materials can be taken } \\
\text { as the price at which it is possible to purchase similar materials as of the specified date }\end{array}$ \\
\hline
\end{tabular}

Источник / Source: разработано автором / developed by the author.

порации, свидетельствующее, в частности, об отсутствии контроля.

Нормативным документом ПБУ 21/2008 «Изменения оценочных значений» ${ }^{4}$ предусматривается определение и подтверждение чистой стоимости продажи запасов, а также закрепление порядка ее расчета в учетной политике корпорацией. Расчет осуществляется на основе информации, доступной до даты подписания бухгалтерской (финансовой) отчетности. При выявлении обесценения материалов корпорация создает резерв под него в размере превышения фактической себестоимости запасов над их чистой стоимостью продажи. Балансовая стоимость материалов определяется посредством корректировки их фактической себестоимости на величину резерва. При изменении чистой стоимости продажи материалов величина резерва подлежит корректировке, но при этом должна быть не выше их фактической себестоимости. Другим

\footnotetext{
${ }^{4}$ Приказ Минфина России от 06.10.2008 № $106 \mathrm{H}$ (ред. от 07.02.2020) «Об утверждении положений по бухгалтерскому учету» (вместе с «Положением по бухгалтерскому учету «Учетная политика организации» (ПБУ 1/2008)», «Положением по бухгалтерскому учету «Изменения оценочных значений» (ПБУ 21/2008)») (Зарегистрировано в Минюсте России 27.10.2008 № 12522). URL: www.consultant.ru/document/ cons_doc_LAW_81164/ (дата обращения: 21.07.2021).
}

документом - ФСБУ 5/2019 «Запасы» ${ }^{5}$ предусматривается отнесение суммы формируемого оценочного резерва на расходы периода, в котором создан (увеличен) резерв под их обесценение. По мнению автора, расходами периода целесообразно признавать суммы резервов, сформированных под обесценение готовой продукции и товаров, в то же время резервы под обесценение материалов, незавершенного производства, иных видов запасов (кроме готовой продукции и товаров) следует признавать в составе прочих расходов. Принятие в учетной политике корпорации предлагаемого порядка основывается на необходимости организации аналитического учета продаж и прочих доходов и расходов по каждому виду проданных товаров, продукции, активов. Рекомендуемая организация формирования резервов под обесценение запасов обеспечит достоверность определения финансового результата проводимых транзакций. В современной теории и практике корпоративного учета в развитие положений ПБУ 5/01

\footnotetext{
${ }^{5}$ Приказ Минфина России от 15.11.2019 N 180н «Об утверждении Федерального стандарта бухгалтерского учета ФСБУ 5/2019 «Запасы» (вместе с «ФСБУ 5/2019...») (Зарегистрировано в Минюсте России 25.03.2020 N 57837).URL: http://www.consultant.ru/document/cons_doc_LAW_348523/ (дата обращения:21.07.2021)
} 


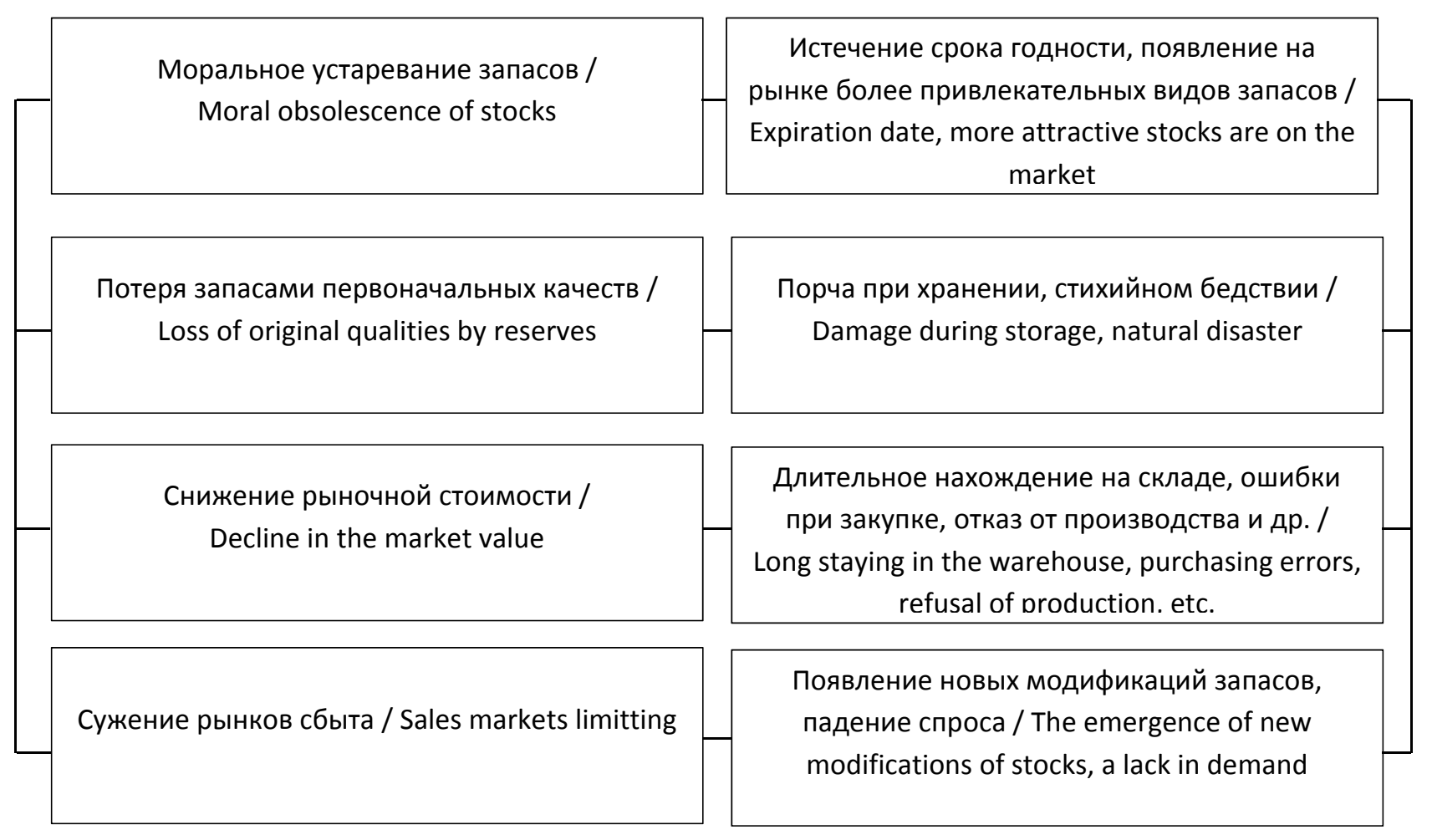

\section{Puc. 1 / Fig. 1. Признаки обесценения запасов / Indicators of depreciation of stocks}

Источник / Source: разработано автором / developed by the author.

«Учет материально-производственных запасов» разработаны отдельные методики формирования резерва под обесценение запасов [15-17]. Ввод в действие ФСБУ 5/2019 «Запасы» вызывает необходимость корректировки методов формирования резерва под обесценение запасов. Исследование показало, что формирование и раскрытие в корпоративном учете и отчетности обесценения запасов вызывает необходимость решения ряда вопросов, в частности, автор утверждает: «Расчет оценочного резерва предполагает определенные трудозатраты, связанные с выявлением обесценившихся запасов, а также определением чистой стоимости продажи. Для осуществления указанной работы целесообразно привлекать должностных лиц, ответственных за закупки, использование, производство и продажу запасов, обесценение которых свидетельствует о недостижении целей деятельности корпорации» [19]. Применение элементов внутреннего контроля позволит управлять рисками утраты собственного капитала вследствие обесценения запасов. Компьютеризация учета и применение информационных бухгалтерских систем позволяет в установленные менеджментом корпорации сроки (ежемесячно, ежеквартально) формировать ведомость обесценения материалов, включающую данные о неиспользуемых материалах и суммах обесценения. Расчетная схема оценки риска утраты собственного капитала в результате обесценения материалов представлена в табл. 4.

Расчет обесценения запасов позволяет оценить риск утраты корпорацией собственного капитала.

На результаты деятельности корпорации большое влияние оказывает производственный риск, связанный с наличием сомнительной дебиторской задолженности, списание которой уменьшает собственный капитал. Дебиторская задолженность корпорации, не погашенная в срок, не обеспеченная гарантиями (залогом, поручительством, банковской гарантией) предполагает формирование в учете оценочного значения - резерва по сомнительным долгам, и включение его суммы в состав прочих расходов. Резерв создается на полную или невозможную к взысканию сумму долга, его величина формируется отдельно по каждому сомнительному долгу и зависит от платежеспособности должника и оценки вероятности погашения долга полностью или частично. Если на отчетную дату имеется уверенность в погашении просроченной дебиторской задолженности, резерв по данному долгу может не создаваться. К сожалению, порядок расчета резерва по сомни- 


\begin{tabular}{|c|c|c|c|c|c|c|c|c|c|c|}
\hline \multirow[b]{2}{*}{$\begin{array}{l}\text { Наиме- } \\
\text { нование } \\
\text { запаса / } \\
\text { Name of } \\
\text { the stock }\end{array}$} & \multirow[b]{2}{*}{$\begin{array}{c}\text { Ед. изме- } \\
\text { рения / } \\
\text { Unit of } \\
\text { measure- } \\
\text { ment }\end{array}$} & \multirow[b]{2}{*}{$\begin{array}{c}\text { Фактиче- } \\
\text { ская себе- } \\
\text { стоимость, } \\
\text { руб./ } \\
\text { Actual cost } \\
\text { price, Rub. }\end{array}$} & \multirow[b]{2}{*}{$\begin{array}{c}\text { Чистая } \\
\text { стоимость } \\
\text { продаж, } \\
\text { pyб./ Net } \\
\text { sales value, } \\
\text { Rub. }\end{array}$} & \multicolumn{3}{|c|}{$\begin{array}{l}\text { Остаток на складе / } \\
\text { Remaining stock in the warehouse }\end{array}$} & \multirow{2}{*}{$\begin{array}{c}\text { Резерв под } \\
\text { обесцене- } \\
\text { ние, руб / } \\
\text { Provision for } \\
\text { impairment, } \\
\text { Rub. } \\
\end{array}$} & \multicolumn{3}{|c|}{$\begin{array}{l}\text { Причины обесценения, ответственное } \\
\text { подразделение / Causes of impairment, } \\
\text { responsible division }\end{array}$} \\
\hline & & & & $\begin{array}{l}\text { Кол-во / } \\
\text { Quantity }\end{array}$ & $\begin{array}{c}\text { Фактиче- } \\
\text { ская себе- } \\
\text { стоимость, } \\
\text { pуб./ Actual } \\
\text { cost price, } \\
\text { Rub. }\end{array}$ & $\begin{array}{c}\text { Чистая } \\
\text { стоимость } \\
\text { продаж, } \\
\text { руб./ Net } \\
\text { sales value, } \\
\text { Rub. }\end{array}$ & & $\begin{array}{c}\text { Ошибки } \\
\text { в расчете } \\
\text { потребно- } \\
\text { сти (отдел } \\
\text { закупок) / } \\
\text { Errors in the } \\
\text { calculation of } \\
\text { demand-news } \\
\text { (purchasing } \\
\text { department) }\end{array}$ & $\begin{array}{c}\text { Аннулирование } \\
\text { договора контр- } \\
\text { агентом } \\
\text { (отдел мар- } \\
\text { кетинга) / } \\
\text { Сancellation of } \\
\text { the contract by } \\
\text { the counterparty } \\
\text { (marketing } \\
\text { department) }\end{array}$ & Иные \\
\hline $\begin{array}{l}\text { Мате- } \\
\text { риал A/ } \\
\text { Material A }\end{array}$ & шт. & 85 & 80 & 1000 & 850000 & 800000 & 50000 & + & & \\
\hline $\begin{array}{l}\text { Мате- } \\
\text { риал Б / } \\
\text { Material B }\end{array}$ & Кг & 100 & 90 & 500 & 50000 & 45000 & 5000 & & + & \\
\hline $\begin{array}{l}\text { Итого / } \\
\text { Total }\end{array}$ & - & - & - & - & 900000 & 845000 & 55000 & - & - & - \\
\hline
\end{tabular}

Источник / Source: разработано автором / developed by the author.

тельным долгам документами, регулирующими бухгалтерский учет, не установлен; как правило, он определяется в учетной политике корпорации на основе профессионального суждения формирующих ее специалистов и оформляется бухгалтерской справкой. При признании дебиторской задолженности впоследствии нереальной для взыскания либо в связи с истечением срока исковой давности, либо по другим причинам она подлежит списанию за счет резерва сомнительных долгов. При этом при расчете могут использоваться вероятностные характеристики, в частности, коэффициент вероятности оплаты, методика определения которых должна содержаться в приказе об учетной политике. Проблемы формирования резерва сомнительных долгов исследовались рядом авторов [16,17].

Начисление или восстановление резерва оформляется бухгалтерской справкой-расчетом. Схема оценки риска утраты собственного капитала в результате обесценения дебиторской задолженности представлена в табл. 5.

Утрата активов и, как следствие, потеря собственного капитала происходит при обесценении финансовых вложений. Основной причиной возникновения риска, по мнению автора, выступает недостаточная проверка финансовой устойчивости эмитентов не только на дату приобретения финансовых вложений, но и в течение их срока обраще- ния в составе активов корпорации. В настоящее время финансовые вложения, по которым возможно определение текущей рыночной стоимости, отражаются в корпоративном учете и отчетности посредством корректировки их учетной стоимости. Разница между оценкой финансовых вложений по учетной стоимости на отчетную дату и предыдущей оценкой включается в состав прочих доходов и расходов корпораций. Устойчивое, существенное снижение стоимости некотируемых финансовых вложений ниже величины экономических выгод, ожидаемых к получению корпорацией в обычных условиях деятельности, признается обесценением финансовых вложений. Характеристиками устойчивого снижения стоимости финансовых вложений являются: превышение учетной стоимостью их расчетной стоимости на отчетную и предыдущую дату; уменьшение расчетной стоимости в течение отчетного периода; отсутствие свидетельств о возможном повышении расчетной стоимости в будущем. В настоящее время ПБУ 19/02 «Учет финансовых вложений» ${ }^{6}$ не содержит порядок расчета резерва под обесценение, что

${ }^{6}$ Приказ Минфина России от 10.12.2002 № $126 \mathrm{H}$ (ред. от 06.04.2015) «Об утверждении Положения по бухгалтерскому учету «Учет финансовых вложений» ПБУ 19/02» (Зарегистрировано в Минюсте России 27.12.2002 № 4085). URL: http://www.consultant.ru/document/cons_doc_LAW_40251/ (дата обращения: 21.07.2021). 
Оценка резерва сомнительных долгов на 30 сентября 2020 г. /

Assessment of the doubtful debts reserve as of September 30, 2020

\begin{tabular}{|c|c|c|c|c|c|c|}
\hline $\begin{array}{c}\text { Наименование } \\
\text { дебитора / Name } \\
\text { of the debtor }\end{array}$ & $\begin{array}{c}\text { Реквизиты } \\
\text { договора / } \\
\text { Contract } \\
\text { details }\end{array}$ & $\begin{array}{c}\text { Обеспечение } \\
\text { возврата } \\
\text { задолженности / } \\
\text { Ensuring the } \\
\text { repayment of debt }\end{array}$ & $\begin{array}{l}\text { Сумма по } \\
\text { договору / } \\
\text { Amount } \\
\text { under the } \\
\text { contract }\end{array}$ & $\begin{array}{c}\text { Срок } \\
\text { оплаты / } \\
\text { Payment term }\end{array}$ & $\begin{array}{c}\text { Период } \\
\text { неисполнения } \\
\text { обязательства, } \\
\text { дней / The period } \\
\text { of non-fulfillment } \\
\text { of the obligation, } \\
\text { days }\end{array}$ & $\begin{array}{c}\text { Сумма, } \\
\text { резерва } \\
\text { руб./ } \\
\text { Amount, } \\
\text { reserve } \\
\text { rub. }\end{array}$ \\
\hline $\begin{array}{l}\text { O०० «Росток» / } \\
\text { Rostock LLC }\end{array}$ & $\begin{array}{c}\text { № } 120 \text { от } \\
15.06 .2020 \text { г. }\end{array}$ & $\begin{array}{l}\text { Неустойка / } \\
\text { Penalty fee }\end{array}$ & 500000 & 24.06.2020 г. & 98 & 500000 \\
\hline PJSC «Impulse» & $\begin{array}{c}\text { № } 124 \text {, от } \\
\text { 5.07. } 2020 \text { г. }\end{array}$ & $\begin{array}{c}\text { Неустойка / } \\
\text { Penalty fee }\end{array}$ & 300000 & 27.07.2020 г. & 65 & 150000 \\
\hline Итого / Total & - & - & 800000 & - & - & 650000 \\
\hline
\end{tabular}

Источник / Source: разработано автором / developed by the author.

Оценка резерва под обесценение финансовых вложений отчетного периода /

Таблица 6 / Table 6 Assessment of the provision for impairment of financial investments of the reporting period

\begin{tabular}{|c|c|c|c|c|c|c|}
\hline \multirow[b]{2}{*}{$\begin{array}{c}\text { Наименование } \\
\text { финансовых } \\
\text { вложений / Name of } \\
\text { financial investments }\end{array}$} & \multirow[b]{2}{*}{$\begin{array}{l}\text { Эмитент, } \\
\text { заемщик / Issuer, } \\
\text { borrower }\end{array}$} & \multirow{2}{*}{$\begin{array}{c}\text { Учетная } \\
\text { стоимость } \\
\text { финансовых } \\
\text { вложений / } \\
\text { The } \\
\text { accounting } \\
\text { value of } \\
\text { financial } \\
\text { investments }\end{array}$} & \multicolumn{3}{|c|}{$\begin{array}{c}\text { Причины обесценения финансовых } \\
\text { вложений / Reasons for the impairment } \\
\text { of financial investments }\end{array}$} & \multirow{2}{*}{$\begin{array}{c}\text { Сумма, } \\
\text { резерва под } \\
\text { обесценение, } \\
\text { руб. / The } \\
\text { amount of the } \\
\text { provision for } \\
\text { impairment, } \\
\text { Rub. } \\
\end{array}$} \\
\hline & & & $\begin{array}{c}\text { банкротство } \\
\text { эмитента, } \\
\text { заемщика / } \\
\text { bankruptcy of } \\
\text { the issuer, the } \\
\text { borrower }\end{array}$ & $\begin{array}{c}\text { снижение } \\
\text { рыночной } \\
\text { стоимости } \\
\text { ценных } \\
\text { бумаг / } \\
\text { decrease in } \\
\text { the market } \\
\text { value of } \\
\text { securities }\end{array}$ & $\begin{array}{c}\text { отсутствие/ } \\
\text { снижение } \\
\text { поступлений } \\
\text { от } \\
\text { финансовых } \\
\text { вложений } \\
\text { absence/ } \\
\text { decrease of } \\
\text { income from } \\
\text { financial } \\
\text { investments }\end{array}$ & \\
\hline $\begin{array}{l}\text { Облигации } \\
\text { с купонным } \\
\text { доходом / Bonds } \\
\text { with coupon income }\end{array}$ & $\begin{array}{c}\text { ПАО «Строитель» / } \\
\text { PJSC «Builder» }\end{array}$ & 600000 & - & - & + & 600000 \\
\hline $\begin{array}{l}\text { Акции } \\
\text { обыкновенные / } \\
\text { Ordinary shares }\end{array}$ & $\begin{array}{l}\text { ПАО «Финансист / } \\
\text { PJSC “Financier" }\end{array}$ & 500000 & + & - & - & 500000 \\
\hline Итого / Total & & 1100000 & + & - & + & 1100000 \\
\hline
\end{tabular}

Источник / Source: разработано автором / developed by the author.

заставляет корпорацию разрабатывать соответствующие методики самостоятельно. Методы определения расчетной стоимости финансовых вложений, содержащие, в основном, вероятностные характеристики, представлены в ряде работ $[16,20]$, но необходимо отметить, что на основании требования осмотрительности учетной политикой корпорации может планироваться формирование резерва под обесценение в полной сумме учетной стоимости финансовых вложений, а его расчет оформляется бухгалтерскими справками, информация о которых обобщена в табл. 6. 


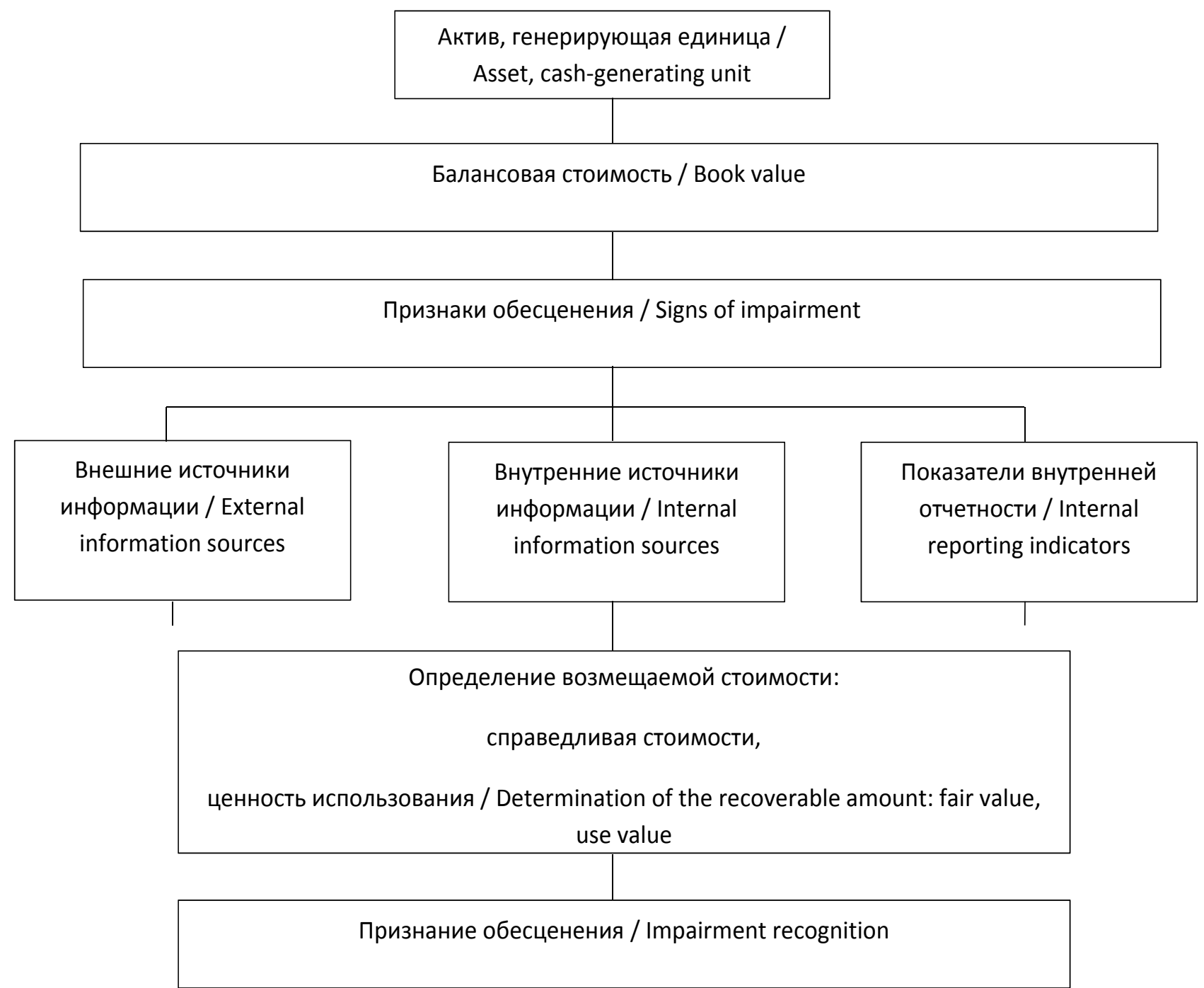

Puc. 2 / Fig. 2. Порядок расчетов по определению обесценения внеоборотных активов / Calculation procedure for determining the impairment of non-current assets

Источник / Source: разработано автором / developed by the author.

Данные табл. 6 позволяют оценить риск утраты собственного капитала в сроки, установленные учетной политикой корпорации, либо по запросу.

Внеоборотные активы корпораций также подвержены риску утраты стоимости, методика оценки которого содержится в МСФО (IAS) 36 «Обесценение активов» ${ }^{7}$. Тестированию на обесценение подлежат нематериальные активы, основные средства, поисковые активы. Отметим, что при тестировании на обесценение также использу-

\footnotetext{
${ }^{7}$ Международный стандарт финансовой отчетности (IAS) 36 «Обесценение активов». URL: https://normativ.kontur.ru/ document?moduleId=1 \&documentId=387810 (дата обращения: 21.07.2021).
}

ется МФО (IFRS) 6 «Разведка и оценка полезных ископаемых» ${ }^{8}$.

Объекты основных средств и нематериальных активов считаются обесценившимися при превышении балансовой стоимости, возмещаемой стоимостью, в качестве которой выступает справедливая стоимость за вычетом затрат на выбытие или стоимость использования (в зависимости от того, какая из данных величин больше).

\footnotetext{
8 Международный стандарт финансовой отчетности (IAS) 6 «Разведка и оценка полезных ископаемых». URL: https:// normativ.kontur.ru/document? moduleId=1 \&documentId=349 594\#10 (дата обращения: 21.07.2021).
} 
Таблица 7 / Table 7

Информация о рисках обесценения активов / Information on the risks of assets impairment

\begin{tabular}{|c|c|c|c|}
\hline $\begin{array}{c}\text { Обесценивающиеся } \\
\text { активы / Impaired } \\
\text { assets }\end{array}$ & $\begin{array}{c}\text { Факторы / } \\
\text { обесценения } \\
\text { Impairment factors }\end{array}$ & $\begin{array}{c}\text { Ответственные подразделения } \\
\text { корпорации / Responsible } \\
\text { divisions of the corporation }\end{array}$ & $\begin{array}{c}\text { Мероприятия по ликвидации } \\
\text { риска / Measures to eliminate } \\
\text { the risk }\end{array}$ \\
\hline $\begin{array}{l}\text { Нематериальные } \\
\text { активы } \\
\text { Основные средства / } \\
\text { Intangible assets } \\
\text { Fixed assets }\end{array}$ & $\begin{array}{l}\text { Внутренние } \\
\text { и внешние / Internal } \\
\text { and external }\end{array}$ & $\begin{array}{l}\text { Производственные } \\
\text { подразделения - использование } \\
\text { нематериальных активов } \\
\text { и основных средств } \\
\text { в производстве. } \\
\text { Подразделение маркетинга - } \\
\text { договоры с потребителями } \\
\text { продукции, работ, услуг. } \\
\text { Бухгалтерия - контроль } \\
\text { соблюдений условий признания } \\
\text { активов / Production units - the } \\
\text { use of non-material assets and } \\
\text { fixed assets in production. } \\
\text { Marketing division - contracts } \\
\text { with consumers of products, works, } \\
\text { services. } \\
\text { Accounting - monitoring } \\
\text { compliance with the conditions for } \\
\text { recognizing assets }\end{array}$ & $\begin{array}{l}\text { Обеспечение использования } \\
\text { внеоборотных активов } \\
\text { в производстве. } \\
\text { Своевременное заключение } \\
\text { договоров с потребителями } \\
\text { продукции, произведенной } \\
\text { с использованием нематериальных } \\
\text { активов. } \\
\text { Формирование информации, } \\
\text { подтверждающей условия } \\
\text { признания активов / Ensuring } \\
\text { the use of non-current assets } \\
\text { in production. } \\
\text { Timely conclusion of contracts with } \\
\text { consumers of products produced } \\
\text { using intangible assets. } \\
\text { Formation of information confirming } \\
\text { the conditions for the recognition of } \\
\text { assets }\end{array}$ \\
\hline Запасы / Stocks & $\begin{array}{l}\text { Моральное } \\
\text { устаревание, потеря } \\
\text { первоначальных } \\
\text { качеств; снижение } \\
\text { рыночной стоимости; } \\
\text { сужение рынков } \\
\text { сбыта / Obsolescence, } \\
\text { loss of original } \\
\text { qualities; decrease in } \\
\text { market value; narrowing } \\
\text { of sales markets }\end{array}$ & $\begin{array}{l}\text { Подразделения ответственные за } \\
\text { закупки, хранение, использование } \\
\text { в экономической деятельности, } \\
\text { сбыт / Departments responsible } \\
\text { for procurement, storage, use in } \\
\text { economic activity, sales }\end{array}$ & $\begin{array}{l}\text { Контроль состояния запасов, } \\
\text { выявление признаков обесценения. } \\
\text { активная сбытовая деятельность / } \\
\text { Control of the state of reserves, } \\
\text { identification of signs of impairment. } \\
\text { active sales activity }\end{array}$ \\
\hline $\begin{array}{l}\text { Дебиторская } \\
\text { задолженность / } \\
\text { Accounts receivable }\end{array}$ & $\begin{array}{l}\text { Оппортунизм } \\
\text { контрагентов / } \\
\text { Opportunism } \\
\text { of counterparties }\end{array}$ & $\begin{array}{l}\text { Подразделения маркетинга / } \\
\text { Marketing departments }\end{array}$ & $\begin{array}{l}\text { Контроля финансового состояния, } \\
\text { правоспособности и дееспособности } \\
\text { контрагентов, способности получать } \\
\text { доходы в будущем, наличие } \\
\text { обеспечения / Control of the } \\
\text { financial condition, legal capacity and } \\
\text { legal capacity of counterparties, the } \\
\text { ability to receive income in the future, } \\
\text { the availability of security }\end{array}$ \\
\hline $\begin{array}{l}\text { Финансовые } \\
\text { вложения / Financial } \\
\text { investments }\end{array}$ & $\begin{array}{l}\text { Оппортунизм } \\
\text { эмитентов, заемщиков, } \\
\text { контрагентов / } \\
\text { Opportunism of } \\
\text { issuers, borrowers, } \\
\text { counterparties }\end{array}$ & $\begin{array}{l}\text { Подразделения, контролирующие } \\
\text { движение финансовых } \\
\text { вложений / Divisions that control } \\
\text { the movement of financial } \\
\text { investments }\end{array}$ & $\begin{array}{l}\text { Контроля финансового состояния, } \\
\text { правоспособности и дееспособности } \\
\text { эмитентов, заемщиков, способности } \\
\text { получать доходы в будущем / The } \\
\text { financial condition control, legal } \\
\text { capacity and legal capacity of issuers, } \\
\text { borrowers, the ability to receive } \\
\text { income in the future }\end{array}$ \\
\hline
\end{tabular}

Источник / Source: разработано автором / developed by the author.

Справедливую стоимость МСФО (IFRS) 13 «Оценка по справедливой стоимости» ${ }^{9}$ определяет

\footnotetext{
${ }^{9}$ Международный стандарт финансовой отчетности (IFRS) 13 «Оценка справедливой стоимости» URL: http:// www.consultant.ru/document/cons_doc_LAW_193740/ (дата обращения: 21.07.2021).
}

как цену, которая была бы получена при продаже актива или уплачена при передаче обязательства в условиях осуществления операции на организованном рынке между его участниками на дату оценки. Ценность использования определяется как приведенная (дисконтированная) стоимость будущих денежных потоков, которые ожидается 
получить от актива или генерирующей единицы. Оценка ценности использования актива предполагает оценку будущих поступлений и оттоков денежных средств, связанных с использованием актива, а также обоснование ставки дисконта.

Об обесценении актива свидетельствуют также показатели внутренней отчетности:

- денежные потоки для приобретения актива или денежные средства, необходимые для его эксплуатации/содержания, значительно превышают сумму, предусмотренную бюджетом;

- фактические чистые денежные потоки, а также операционная прибыль или убыток, обеспечиваемые активом, существенно хуже планируемых показателей;

- отмечено связанное с активом снижение чистых денежных потоков, операционной прибыли, а также увеличение убытков, предусмотренных бюджетом;

- текущие и перспективные бюджеты свидетельствуют об операционных убытках, чистых оттоках денежных средств, связанных с использованием актива.

Отдельными нормативными документами в области бухгалтерского учета предусматривается списание внеоборотных и оборотных активов, не приносящих экономические выгоды. Отраслевым комитетом связи (ОК Связь) принята Рекомендация Р-121/2020-ОК Связь «Выявление неиспользуемых материальных активов» ${ }^{10}$, предусматривающая списание с учета и исключение из отчетности информации о нематериальных активах, не приносящих выгоды корпорации, в связи с прекращением их использования и отсутствием перспектив его возобновления (неиспользуемые нематериальные активы). Документом отмечается, что нематериальный актив, не обеспечивающий экономические выгоды корпорации в результате прекращения его использования, согласно статье 10 Федерального закона «О бухгалтерском учете», может рассматриваться как мнимый объект бухгалтерского учета, отраженный там лишь для вида. К мнимым объектам учета и элементам бухгалтерской (финансовой) отчетности можно отнести запасы, не используемые корпорацией и длительное время находящиеся на складах, обес-

\footnotetext{
${ }^{10}$ Рекомендация Р-121/2020-ОК СВЯзь «Выявление неиспользуемых нематериальных активов». URL: http:// bmcenter.ru/Files/R-OK_Svyaz_Uchet_NMA_s_nulevoi_ stoimostiy (дата обращения: 21.07.2021).
}

ценившиеся финансовые вложения, сомнительную дебиторскую задолженность.

\section{ВЫВОДЫ}

Наличие в бухгалтерском учете и бухгалтерской (финансовой) отчетности информации о неиспользуемых основных средствах, нематериальных активах, запасах, не обеспечивающих дохода финансовых вложениях, снижает надежность сведений, не позволяет пользователям принять обоснованные экономические решения. Корректность в обеспечении достоверности стоимостного измерения активов вносит предлагаемая автором оценка рисков, раскрывающая потери корпораций. Проведенное исследование позволяет выявить причины возникновения рисков и активы, не обеспечивающие корпорации экономические выгоды, но обуславливающие расходы, в частности амортизационные отчисления, платежи в Роспатент, оплату хранения и другие. Предлагаемые методы оценки рисков обеспечивают корректность в обеспечении достоверности стоимостного измерения активов и позволяют оценить потери собственного капитала.

Автор считает, что Минфину России целесообразно включить в состав рисков корпораций, подлежащих раскрытию в бухгалтерской (финансовой) отчетности, наряду с правовыми, страновыми, региональными, репутационными рисками также риски утраты собственного капитала вследствие обесценения активов.

Систематизацию информации о рисках целесообразно осуществлять в корпоративных стандартах, применение которых рекомендовано Федеральным законом «О бухгалтерском учете», т.е. в распорядительных документах, формируемых на основании профессионального суждения специалистов в области учета и отчетности. Необходимость и порядок их разработки, утверждения, изменения и отмены устанавливаются корпорацией. Особое внимание при оценке риска должно уделяться анализу рискообразующих факторов и внедрению мероприятий по их устранению. Рекомендуемый формат раздела корпоративного стандарта, позволяющего обобщить информацию о рисках утраты собственного капитала корпорации вследствие обесценения активов, представлен в табл. 7.

Поскольку обесценение активов уменьшает собственный капитал корпорации и повышает риск ликвидности, то оценка риска утраты собст- 
венного капитала призвана подтвердить наличие отраженных в бухгалтерском учете активов корпораций и надежность их оценки. Корпорациям, формирующим публичную отчетность, следу- ет в пояснениях к бухгалтерской (финансовой) отчетности раскрывать информацию о рисках, позволяющую заинтересованным сторонам принимать обоснованные экономические решения.

\section{СПИСОК ИСТОЧНИКОВ}

1. Шумпетер Й. Теория экономического развития. Пер. с немецкого. М.: Прогресс; 1982. 456 с.

2. Hull J.C. Options, Futures, and Other Derivatives, 9th ed. Pearson Longman. 2015.

3. Glasserman P., Xu.X Robust Risk Measurement and Model Risk. Quantitative Finance. 2014;14(1): $29-58$.

4. Hull J.C. Risk Management and Financial Institutions, New York: Wiley; 2015.

5. Базел Р., Кокс Д., Браун Р. Информация и риск в маркетинге. Пер с англ. М.: Финстатинформ; 1993. 93 c.

6. Contarek W. Risk governance of financial institutions: The growing importance of risk appetite and culture. Journal of risk Management in Financial institutions. 2016;9(2):120-129.

7. Ливингстон Г. Дуглас Г. Анализ рисков операций с облигациями на рынке ценных бумаг. Пер. с англ. М.: Филин; 1998. 448 с.

8. Поленова С.Н. Информация о рисках: раскрытие в бухгалтерской (финансовой) отчетности. Aудит и финансовый анализ.2014;(3):75-78.

9. Балабанов И.Т. Риск-менеджмент. М.: Финансы и статистика; 1996. 192 с.

10. Катасонов В.Ю., Морозов Д.С. Проектное финансирование: организация, управление риском, страхование. М.: Анкил; 2000. 270 с.

11. Лапуста М.Г., Шаршукова Л.Г. Риски в предпринимательской деятельности. М.: ИНФРА-М; 1998. 223 с.

12. Федорец А.Г. Методические основы количественного оценивания производственных рисков. Охрана труда. 2008;3(20):10-12.

13. Бороненкова С.А., Власова И.Е., Буянова Т.И. Совершенствование учетного обеспечения управления имущественными рисками. Аудит. 2018;(6):28-31.

14. Damodaran A. Investment Valuation: Tools and Techniques for Determining the Value of Any Asset, $3^{\text {rd }}$ ed. New York: Wiley; 2012. 992 p.

15. Кеворкова Ж.А. Обесценение активов как метод реализации принципа осмотрительности. Калуга: АКФ «Политоп»; 2017. 112 с.

16. Куликова Л.И., Губайдуллина А.Р. Профессиональное суждение бухгалтера как инструмент формирования финансовой отчетности: М.: Проспект; 2016. 128 с.

17. Петрова В.Ю. Раскрытие информации о резервах в бухгалтерской отчетности. Бухгалтерский учет.2019;(1):50-59.

18. Сапожникова Н.Г. Информация о рисках в корпоративной отчетности. Финансы. Экономика, Стратегия. $2014 ;(6): 17-21$.

19. Сапожникова Н.Г. Обесценение активов и риски корпораций Вестник Воронежского государственного университета. Серия. Экономика и управление. 2020;(2):105-115.

20. Селезнева И.П. Развитие методики оценки и бухгалтерского учета финансовых вложений. Международный бухгалтерский учет. 2015;18(18):15-31.

\section{REFERENCES}

1. Schumpeter J. Theory of economic development. Trans. from German. M.: Progress; 1982. 456 p. (In Russ.).

2. Hull J. C. Options, futures, and other derivatives, 9th ed. Pearson Longman. 2015.

3. Glasserman P., Xu.X. Robust risk measurement and model risk. Quantitative Finance. 2014;14 (1):29-58.

4. Hull J.C. Risk management and financial institutions, NY: Wiley; 2015.

5. Basel R., Cox D., Brown R. Information and risk in marketing. Trans. from English. M.: Finstatinform; 1993. 93 p. (In Russ.).

6. Contarek W. Risk governance of financial institutions: The growing importance of risk appetite and culture. Journal of risk management in financial institutions. 2016;9(2):120-129. 
7. Livingston G., Douglas G. Analysis of the risks of operations with bonds on the securities market. Trans. from English M.: Filin; 1998. 448 p. (In Russ.).

8. Polenova S. N. Risk information: Disclosure in accounting (financial) statements. Audit and financial analysis. 2014;(3):75-78. (In Russ.).

9. Balabanov I.T. Risk management. Moscow: Finance and Statistics; 1996192 p. (In Russ.).

10. Katasonov V. Yu., Morozov D. S. Project financing: Organization, risk management, insurance. M.: Ankil; 2000. 270 p. (In Russ.).

11. Lapusta M. G., Sharshukova L. G. Business risks. M.: INFRA-M; 1998. 223 p. (In Russ.).

12. Fedorets A.G. Methodological foundations for quantitative assessment of production risks. Occupational Safety and Health. 2008;3(20):10-12. (In Russ.).

13. Boronenkova S. A., Vlasova I.E., Buyanova T. I. Improvement of accounting support for property risk management. Audit. 2018;(6):28-31. (In Russ.).

14. Damodaran A. Investment valuation: Tools and techniques for determining the value of any asset. 3rd ed. NY: Wiley; 2012. $992 \mathrm{p}$.

15. Kevorkova Zh. A. Impairment of assets as a prudence method. Kaluga: ACF «Polytop»; 2017. 112 p. (In Russ.).

16. Kulikova L.I., Gubaidullina A.R. Professional judgment of an accountant as a tool for generating financial statements: M.: Prospectus; 2016. 128 p. (In Russ.).

17. Petrova V. Yu. Disclosure of information on reserves in the financial statements. Accounting. 2019;(1):5059. (In Russ.).

18. Sapozhnikova N. G. Information about risks in corporate reporting. Finance. Economics, Strategy. 2014;(6):17-21. (In Russ.).

19. Sapozhnikova N. G. Asset impairment and corporate risks. Bulletin of Voronezh State University. Series. Economics and management. 2020;(2):105-115. (In Russ.).

20. Selezneva I. P. Development of methods for assessing and accounting for financial investments. International accounting. 2015;18(18):15-31. (In Russ.).

\section{ИНФОРМАЦИЯ ОБ АВТОРЕ}

Наталья Глебовна Сапожникова - доктор экономических наук, профессор, заведующая кафедрой экономической безопасности и бухгалтерского учета, Воронежский государственный университет, Воронеж, Россия

sapozh@yandex.ru

\section{ABOUT THE AUTHOR}

Natalya G. Sapozhnikova - Dr. Sci. (Econ.), Professor, Head of the department of Economic Security and Accounting, Voronezh State University, Voronezh, Russia sapozh@yandex.ru

Статья поступила в редакцию 06.08.2021; после рецензирования 30.08.2021; принята к публикации 13.09.2021.

Автор прочитала и одобрила окончательный вариант рукописи.

The article was submitted on 06.08.2021; revised on 30.08.2021; and accepted for publication on 13.09.2021.

The author read and approved the final version of the manuscript. 